\title{
Changes in social behavior of Macaca fuscata yakui in relation to unfamiliar objects
}

\author{
ETHEL TOBACH \\ American Museum of Natural History, New York, New York \\ KIYOKO MUROFUSHI \\ Primate Research Institute, Kyoto University, Inuyama, Japan \\ JOHN BEATTY \\ Brooklyn College, New York, New York \\ and \\ JUNICHI TAKAHASHI \\ City University of New York, New York, New York
}

\begin{abstract}
A troop of captive Macaca fuscata yakui (Japanese monkey)-consisting of 1 infant, 3 yearlings, 2 3-year-old females, 10 adult females, and 3 adult males-was presented with four large, unfamiliar objects, which the animals manipulated in fine and gross motor patterns. The infant and the yearlings acted on the objects in social groups, whereas the others manipulated the objects as individuals. This may be relevant to the fact that when the objects were present, females stopped carrying the young and female-female mounting decreased while female-female threat behavior increased. When the objects were removed, there was an increase in hostile behavior among the females and males.
\end{abstract}

Some attempts have been made to examine primate reactions to novel objects (Menzel, 1966) and social aspects of spatial behavior in novel situations (Hughes \& Menzel, 1973; Menzel, 1969). Attention has not been focused, however, on changes in social relations among members of a group in relation to the reactions to novel objects. The observations reported here provide evidence that the introduction of novel objects significantly affects social behavior and relationships in a group.

A troop of 19 Macaca fuscata yakui were maintained in an enclosure $\left(68 \mathrm{~m}^{2}\right)$ and cage $\left(15 \mathrm{~m}^{2}\right)$ for more than 1 year at the Primate Research Institute, Kyoto University. Their behavior was observed for 3 days before, 3 days during, and 3 days after placement of two novel objects in the cage and two in the enclosure.

The two objects were an open-ended cylinder $70 \mathrm{~cm}$ long, with a diameter of $68 \mathrm{~cm}$ at one end and $60 \mathrm{~cm}$ at the other, and a completely closed cylinder ("drum") $40 \mathrm{~cm}$ long, with a diameter of $35 \mathrm{~cm}$ at one end and

This research was supported by grants from the National Science Foundation to Ethel Tobach and John Beatty, from Brooklyn College to John Beatty, and from the National Institute of Mental Health to Ethel Tobach. We also wish to thank the Primate Research Institute of Kyoto University and the American Museum of Natural History for their support. We would especially like to thank Sumihara Nagumo of the Primate Research Institute for his technical assistance. A 16-mm movie of the behavior of the animals is available from $\mathrm{E}$. Tobach.

Ethel Tobach's address is: American Museum of Natural History, Central Park West at 79th Street, New York, NY 10024.
$30 \mathrm{~cm}$ at the other. The drum was filled with loose rocks. Both were made of blue plastic. The objects were chosen for their durability; for their difference from any previously known objects during the animals' stay at the Institute; for their size, which permitted easy observation of manipulation in a variety of behavioral patterns to maximize the possibility of novel activity; and for their potential to stimulate action and interaction.

The troop consisted of 1 infant approximately 3 months old, 3 yearlings, 2 3-year-old females (juveniles), $10 \mathrm{fe}$ males ranging in age from 6 to 17 years, and 3 adult males of uncertain ages. Data were recorded for classes of animal (i.e., infant, yearlings, juveniles, adult females, and adult males), rather than for individuals. As the recorded behavior of the juvenile and adult females did not yield statistically significant differences, they were considered as one class, females. The same was true of the infant and yearlings.

Four observers were stationed at posts around the top of the enclosure and above the ceiling of the cage. The ceiling was an open grating of bars through which the entire cage was easily seen. Paper and pencil protocols were used. A code for previously defined behavior patterns was generated during a preliminary period, in which interobserver reliability was established. Code symbols were entered on area diagrams appropriate to each observer, each diagram page being used to record data for $5 \mathrm{~min}$. Observations of $20 \mathrm{~min}$ each were made seven times daily. 
Table 1

Number of 5-min Periods in Which Behavior Patterns Were Observed

\begin{tabular}{|c|c|c|c|c|c|}
\hline Pattern & $\begin{array}{c}\text { Before } \\
\text { Objects In } \\
\end{array}$ & $\begin{array}{c}\text { During Time } \\
\text { Objects In }\end{array}$ & $\begin{array}{c}\text { After Objects } \\
\text { Removed }\end{array}$ & Statistics & $p$ \\
\hline $\begin{array}{l}\text { Adults with } \\
\text { young }\end{array}$ & 8 & 1 & 10 & $x^{2}(2)=7.05$ & $<.05$ \\
\hline $\begin{array}{l}\text { Adults with } \\
\text { adults only }\end{array}$ & 1 & 7 & 2 & $\begin{array}{c}\text { Fisher Exact } \\
\text { Probability }\end{array}$ & $<.01$ \\
\hline $\begin{array}{l}\text { Females carrying } \\
\text { young }\end{array}$ & 16 & 0 & 12 & $\chi^{2}(2)=14.85$ & $<.001$ \\
\hline $\begin{array}{l}\text { Female-female } \\
\text { mounting }\end{array}$ & 11 & 2 & 11 & $x^{2}(2)=6.75$ & $<.05$ \\
\hline $\begin{array}{l}\text { Female-female } \\
\text { threat }\end{array}$ & 4 & 13 & 5 & $x^{2}(2)=6.63$ & $<.05$ \\
\hline $\begin{array}{l}\text { Chasing among } \\
\text { females }\end{array}$ & 17 & 10 & 32 & $\chi^{2}(2)=12.84$ & $<.01$ \\
\hline $\begin{array}{l}\text { Chase resulting } \\
\text { in fighting }\end{array}$ & 8 & 5 & 17 & $x^{2}(2)=7.80$ & $<.05$ \\
\hline
\end{tabular}

Note-Fisher exact probability test compared periods before objects in with periods during time objects in, and periods during time objects in with periods after objects removed.

Four of the observation periods were in the early morning, in connection with cage cleaning and feeding, and three were in the late afternoon. Both times of day had been found to be the most active periods for the animals.

Each 5-min period in which a behavior pattern of a class of animals occurred was counted, regardless of its frequency or duration; thus, any activity could receive a count of four as the highest score for any one 20-min observation. Table 1 shows the number of 5-min periods in which each behavior pattern was observed.

Striking changes were seen in social behavior in relation to the presence or absence of the objects, both in regard to the relationship between adults and infant/yearlings and in regard to adult behavior. When the objects were present, the adults were seen together without the young more frequently than when the objects were not present. Furthermore, when the objects were not present, the females were seen to carry the infant and the yearlings; when the objects were present, the females never carried the young.

Analysis of the behavior of the young monkeys suggests the source of these changes. The infant and yearlings acted differently with the objects than did the adults. The infant/yearlings were active in more periods with the cylinder (68) than with the drum (30), whereas the adults were active with both for an approximately equivalent number of periods [51 and 55 , respectively; $\chi^{2}(1)=9.48$, $p<.01]$.

The infant and yearlings were more often active with the objects in a social context (i.e., 2 or more individuals were seen together in active involvement with the object) than individually (59 out of 98 observation periods), whereas the adults were more often active with the objects when alone [ 89 out of 106 periods; $\chi^{2}(1)=42.49$, $p<.001]$.
Interfemale activity also changed. While the objects were present, female-female mounting decreased significantly and threat behavior among the females tended to increase, while chasing among females decreased.

The change in social behavior may have been primarily a function of the activity of the young animals with the objects (French, 1981). When the infant and yearlings were active with the objects, perhaps they were, in effect, not available to the females for typical bonded interaction. This disruption of bonded behavior may have been a stressor and may have affected the females endocrinologically and behaviorally (Martin, 1985). For example, the decrease in mounting behavior, the lack of infant and yearling carrying by females, and the increase in threat behavior may have been related to the effects of stress on more than one level.

We also found a significant increase in chases that resulted in serious fighting when the objects were removed at the end of the second 3-day period. The females may have focused on themselves in stress-attenuating behavior, inasmuch as their self-grooming increased, although not significantly (before $=14$; during $=22$; after $=11)$ (see Goosen, 1981; Minami, 1975; Troisi, D'Amato, Fuccillo, \& Schucchi, 1982). Rosenblum, Jaufman, \& Stynes (1966) and Terry (1970) reported self-grooming ("displacement behavior," in their terms) as a response to stress. The increase in hostile behavior to others may have been in response to the stress-inducing change in the young's behavior. When the youngest members of the troop became available after the objects were removed, the increase in chasing and fighting may have reflected a return to the previous bonded relationships between females and young, which then negatively affected relationships among the adults.

Recent studies with rhesus monkeys (Macaca mulatta) 
indicate the existence of social mechanisms that restore relationships disturbed by aggression caused by changes in food provisioning (de Waal, 1984; De Waal \& Yoshihara, 1983). Such social processes may have been involved in this study.

\section{REFERENCES}

DE WAAL, F. B. M. (1984). Coping with social tension: Sex differences in the effect of food provision to small rhesus monkey groups. Animal Behaviour, 32, 756-773.

DE WAal, F., \& YoshIHARA, E. (1983). Reconciliation and redirected affection in rhesus monkeys. Behaviour, 85, 224-241.

FRENCH, J. A. (1981). Individual differences in play in Macaca fuscata: The role of maternal status and proximity. International Journal of Primatology, 2, 237-246.

Goosen, C. (1981). On the function of allogrooming in Old-World monkeys. In A. B. Chirelli \& R. S. Coruccini (Eds.), Primate behaviour and sociobiology: Selected papers (Part B) of the VIIIth Congress of the International Primatological Society, Florence, 7-12 July, 1980 (pp. 110-120). Berlin: Springer-Verlag.

Hughes, G. H., \& MenZel, E. W., JR. (1973). Use of space and reac- tions to novel objects in Gelada baboons (Theropithecus gelada). Journal of Comparative \& Physiological Psychology, 83, 1-6.

Martin, C. R. (1985). Endocrine physiology. New York: Oxford University Press.

MenZeL, E. W., JR. (1966). Responsiveness to objects in free-ranging Japanese monkeys. Behaviour, 26, 130-150.

MENZEL, E. W., JR. (1969). Chimpanzee utilization of space and responsiveness to objects. In C. R. Carpenter (Ed.), Behaviour: Proceedings of the Second International Congress of Primatology (Vol. 1, pp. 72-80). New York: Karger.

MiNAMI, T. (1975). Early mother-infant relations in Japanese monkeys. Contemporary primatology, 5th International Congress of Primatology (pp. 334-340). Basel: Karger.

Rosenblum, L. A., Jaufman, I. C., \& Stynes, A. J. (1966). Some characteristics of adult social and autogrooming patterns in two species of macaque. Folia Primatologica, 4, 438-451.

Terry, R. L. (1970). Primate grooming as a tension reduction mechanism. Journal of Psychology, 76, 129-136.

Troisi, M. A., D'Amato, F. R., Fuccillo, R., \& Schucchi, S. (1982). Diurnal pattern of allogrooming in a group of Japanese macaques (Macaca fuscata fuscata Blyth). Monitore Zoologico Italiano (New Series), 16, 149-160.

(Manuscript received for publication September 27, 1986.) 